\title{
Genetic risk for asthma, allergic rhinitis, and atopic dermatitis
}

\author{
Sigrid Dold, Matthias Wjst, Erika von Mutius, Peter Reitmeir, Eva Stiepel
}

\begin{abstract}
In order to explore the genetic risk of a child with a family history of allergies developing asthma, allergic rhinitis, or atopic dermatitis, questionnaires filled in by 6665 families were analysed. The data were collected in a population based cross sectional survey of 9-11 year old schoolchildren living in Munich and southern Bavaria. The relation between asthma, allergic rhinitis, and atopic dermatitis and the number of allergic first degree relatives, and the type of allergic disease was examined. Analyses were done separately for families with single or multiple allergic diseases. In families with one allergic parent the risk of the child developing asthma was increased by asthma in a parent, with an odds ratio $(O R)$ of $2.6(95 \%$ confidence interval 1.7 to 4.0) but not by parental allergic rhinitis with OR $1.0(0.7$ to 1.5$)$ or atopic dermatitis, OR $1.0(0.6$ to 1.6). For allergic rhinitis the highest risk with OR 3.6 (2.9 to 4.6) was observed with allergic rhinitis of one parent, apparently lower for asthma of one parent, OR 2.5 (1.6 to $4 \cdot 0)$ or atopic dermatitis, OR $1.7(1.1$ to $2 \cdot 5)$. Children with parental atopic dermatitis had a high risk for atopic dermatitis, OR 3.4 (2.6 to 4.4), compared with children with parental asthma, OR $1.5(1.0$ to 2.2$)$, or parental allergic rhinitis, OR $1.4(1.1$ to 1.8$)$. Risk factors in families with combined allergies of two relatives (parents and siblings) were analysed separately for the different combinations. These results support the hypothesis that asthma, allergic rhinitis, and atopic dermatitis are multifactorial diseases brought about by various familial and environmental influences.
\end{abstract}

(Arch Dis Child 1992;67:1018-1022)

Environmental and hereditary factors are the most important causes of allergies. Little is known about the interaction between genetics and environment and how they influence the manifestation and severity of allergies.

In 1923, Coca and Cooke introduced the concept of atopy to describe allergies of a familial or hereditary nature, which included asthma, allergic rhinitis, atopic dermatitis, urticaria, and food allergies. ${ }^{1}$ Whereas in the past recessive and dominant models were discussed, ${ }^{2}{ }^{3}$ the results of studies in the last 30 years implicate a multifactorial determination. ${ }^{4-7}$ The variability of manifestation and severity, the polymorbidity, and the different organ systems involved make it difficult to locate the hereditary base and its molecular genetic mechanisms.
Because of the small number of cases involved in many of the studies and the fact that overlapping effects of multiple diseases in the families were not taken into consideration, ${ }^{9-13}$ it has not to date been possible to determine clearly the risk factors for different atopic family situations.

A population based epidemiological survey with a high number of cases should permit a more differentiated examination of the risk due to heredity. The selection of subgroups with a homogeneous allergic family situation allows the estimation of individual risk factors.

The Munich Asthma and Allergy Study is a cross sectional study to determine the prevalence of allergic and asthmatic diseases in schoolchildren in Bavaria. The relationship between atopic diseases of the parents and siblings and the risk of the investigated child developing an allergic disease such as asthma, allergic rhinitis, or atopic dermatitis is analysed with the data from questionnaires completed by 6665 families.

\section{Methods}

The data reported in this paper were collected as part of the Munich Asthma and Allergy Study from October 1989 to July 1990. This survey comprised 9349 schoolchildren aged 9 to 11 years, including all fourth grade children in 118 primary schools in Munich and 65 schools in southern Bavaria. The schools in the rural districts were selected for lower air pollution. Questionnaires were sent home from school with the children, answered by their parents, returned to school, and collected by the investigators. The response rate was $88 \%(8204$ questionnaires). This was an informed consent study approved by the ethics commission of the 'Bayerische Landesärztekammer'.

\section{QUESTIONNAIRE}

Both current and previous allergic diseases of the child and its relatives were evaluated using a total of 58 questions. The questionnaire was standardised according to the recommendation of the American Thoracic Society and supplemented by some of our own questions.

Information given by the parents that a physician had diagnosed asthma at least once or there had been multiple episodes of wheezy bronchitis ('spastische, isthmoide Bronchitis') was taken as representing asthma. Allergic rhinitis was used synonymously with hay fever. Eczema, neurodermatitis, or itching skin lesions in typical locations were interpreted as atopic dermatitis. 
The question 'Did you or a family member ever suffer from one of the following diseases?' was answered separately for the parents, siblings, and grandparents by means of a chart which was divided into sections for bronchial asthma, allergic rhinitis, and atopic dermatitis. Familial allergy was taken to exist when it was stated that at least one family member had at some time asthma, allergic rhinitis, or atopic dermatitis. To estimate the risk of developing asthma, allergic rhinitis, or atopic dermatitis only the data of first degree relatives, parents and siblings, were included.

Because of possible language difficulties and ethnic differences, only questionnaires from German children were considered for evaluation. The response rate of the German children could be estimated only indirectly. In all the primary schools in Munich (from first grade to fourth grade) $24 \%$ of children and in southern Bavaria less than $5 \%$ are non-German. Considering these figures the response rate for German children was about $89 \%$. The child's sex, nationality, place of residence (Munich/southern Bavaria), parents' education, the number of cigarettes smoked at home, and the person who filled in the questionnaire were analysed as possible confounding variables.

\section{STATISTICS}

Only data of first degree family members were included, the grandparents' allergies were not taken into consideration. In analysing the effect of an allergic disease of a sibling or of more than two allergic first degree relatives, children who had no siblings were excluded. To avoid the overlapping effects of multiple genetic disposition, we analysed the genetic risk of different family histories in successive steps. Firstly, additional allergic diseases of other first degree relatives were excluded and the prevalence of the different diseases in children with a positive family history involving one family member was compared with children whose first degree relatives had no atopic disease. Secondly, only

Table 1 Prevalence of asthma, allergic rhinitis, and atopic dermatitis in relation to the number of first degree relatives with an allergic disease. Results are number (\%)

\begin{tabular}{|c|c|c|c|}
\hline Family history & Asthma & Allergic rhinitis & Atopic dermatitis \\
\hline \multirow{5}{*}{$\begin{array}{l}\text { No allergic family history } \\
\text { Allergic disease of: } \\
\text { One sibling } \\
\text { One parent } \\
\text { Both parents } \\
\text { More than two first } \\
\text { degree relatives }\end{array}$} & $257 / 3995(6)$ & $240 / 3984(6)$ & $553 / 3690(15)$ \\
\hline & $47 / 553(9)^{*}$ & $56 / 555(10)^{* 1 *}$ & $115 / 520(22)^{*: *}$ \\
\hline & $109 / 1279(9)^{*}$ & $207 / 1280(16)$ & $317 / 1219(26)$ \\
\hline & 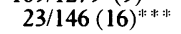 & $36 / 146(25)^{*}$ & $55 / 137(40)^{*}$ \\
\hline & $30 / 170(18)^{\text {w: }: \text { : : }}$ & $47 / 170(28)^{* n+1}$ & $75 / 162(46)^{1+1 * 1}$ \\
\hline
\end{tabular}

Significance in relation to the group with no family history of allergies, ${ }^{*} p<0.05 ;{ }^{*} p<0.01$ ${ }^{*} p<0 \cdot 001$.

Table 2 Prevalence of asthma, allergic rhinitis, and atopic dermatitis in relation to the type of allergy of one parent with an allergic disease. Results are number $(\%)$

\begin{tabular}{|c|c|c|c|}
\hline Family history & Asthma & Allergic rhinitis & Atopic dermatitis \\
\hline $\begin{array}{l}\text { No allergic family history } \\
\text { One parent with: }\end{array}$ & $257 / 3995(6)$ & $240 / 3984(6)$ & $553 / 3690(15)$ \\
\hline $\begin{array}{l}\text { Asthma } \\
\text { Allergic rhinitis } \\
\text { Atopic dermatitis }\end{array}$ & $\begin{array}{l}34 / 252(13)^{*}: k \\
63 / 783(8) \\
35 / 402(9)\end{array}$ & $\begin{array}{r}38 / 251(15) \\
152 / 786(19) \\
49 / 401(12)\end{array}$ & $\begin{aligned} 51 / 237 & (22) \\
170 / 751 & (23) \\
149 / 381 & (39)\end{aligned}$ \\
\hline
\end{tabular}

single allergic diseases in one parent were evaluated. Thirdly, the effect of different combinations of two allergic diseases in two first degree relatives was estimated.

The risk of an allergic family history is given as an odds ratio (OR) with the corresponding 95\% confidence interval (CI). Frequencies were compared for their statistic significance with the $\chi^{2}$ test. All analyses were carried out with SAS $5 \cdot 18$.

\section{Results}

The analysis was based on a total of 6665 questionnaires filled in by Germans, as defined by the nationality of the examined child. The 1539 foreign children were a heterogenous group, of whom $31 \%$ (470) were Turkish, $29 \%$ (443) Yugoslavian, and $41 \%(626)$ were from elsewhere. There were significant differences between German and non-German children in the prevalence of asthma, allergic rhinitis, and atopic dermatitis. ${ }^{14}$

A history of bronchial asthma, allergic rhinitis, and atopic dermatitis of at least one family member (parents, siblings, and grandparents, all with lifetime prevalence) was reported in $47 \%$ (3160) of the German families. Including only data from parents and siblings, $40 \%(2650)$ had a positive family history. In $15 \%$ (1024) of the families there was more than one allergic disease-that is, one or more first degree relatives suffered from one or more allergies. A total of $27 \%$ of the children (1776) had one parent suffering from one atopic disease. Allergy of both parents was reported in $4 \%$ (241) of the families and 3\% (171) had more than two first degree relatives with atopic disease.

Children with atopic disease (asthma, allergic rhinitis, or atopic dermatitis) had a positive family history (first degree relatives) in $55 \%$ of cases compared with $35 \%$ in children without an atopic disease $(\mathbf{p}<0.001)$. The cumulative prevalence of allergies increased with the number of atopic first degree relatives. An allergy of both parents was associated with an allergy in the child in $56 \%$ of cases $(77 / 137)$. There was no difference if the parents had the same type of allergic manifestation $(55 \%, 45 / 82)$. In families with more than two allergic first degree relatives, $67 \%(109 / 163)$ of the children had an allergic disease.

The prevalence of asthma, allergic rhinitis, and atopic dermatitis was associated with the number of allergic family members (table 1). However, differentiation between the types of allergic disease in families with one allergic parent showed that the risk of asthma rose only if asthma was present in a parent, rather than allergic rhinitis or atopic dermatitis (table 2).

Allergic rhinitis was seen in $16 \%$ of the children with one allergic parent, in $25 \%$ if both parents had an allergy, and in $28 \%$ with more than two allergic family members (table 1). In families with one atopic parent, allergic rhinitis of the child was most frequent if a parent also had allergic rhinitis (table 2).

Atopic dermatitis similarly increased with the number of allergic family members, from $26 \%$ with one parent suffering from an allergy, to 
$40 \%$ with both parents allergic, and $46 \%$ in families with more than two allergic subjects. With regard to the type of allergy, the highest risk for atopic dermatitis was observed when a parent also had atopic dermatitis (39\%), while it was evidently lower for allergic rhinitis $(23 \%)$ or asthma (22\%) (table 2).

In comparing the prevalence of allergies associated with different types of parental

Table 3 Child's asthma in relation to one allergic disease of one of the parents and exclusion of additional allergic diseases of first degree relatives. Results are number (\%)

\begin{tabular}{|c|c|c|c|}
\hline Family history & Boys & Girls & Total \\
\hline $\begin{array}{l}\text { No allergic family history } \\
\text { One parent with asthma } \\
\text { OR ( } 95 \% \mathrm{CI}) \\
\text { Mother with asthma } \\
\text { OR ( } 95 \% \mathrm{CI}) \\
\text { Father with asthma } \\
\text { OR ( } 95 \% \mathrm{CI}) \\
\text { One parent with allergic rhinitis } \\
\text { OR ( } 95 \% \mathrm{CI}) \\
\text { One parent with atopic dermatitis } \\
\text { OR ( } 95 \% \mathrm{CI})\end{array}$ & $\begin{array}{l}149 / 1914(8) \\
14 / 89(16) \\
2 \cdot 2(1 \cdot 2 \text { to } 4 \cdot 0) \\
4 / 51(8) \\
1 \cdot 0(0 \cdot 4 \text { to } 2 \cdot 8) \\
10 / 38(26) \\
4 \cdot 2(2 \cdot 0 \text { to } 8 \cdot 9) \\
29 / 329(9) \\
1 \cdot 1(0 \cdot 8 \text { to } 1 \cdot 7) \\
10 / 160(6) \\
0 \cdot 8(0 \cdot 4 \text { to } 1 \cdot 5)\end{array}$ & $\begin{array}{l}108 / 2080(5) \\
11 / 82(13) \\
2 \cdot 8(1 \cdot 5 \text { to } 5 \cdot 5) \\
5 / 47(11) \\
2 \cdot 2(0 \cdot 8 \text { to } 5 \cdot 6) \\
6 / 35(17) \\
3 \cdot 8(1 \cdot 5 \text { to } 9 \cdot 3) \\
14 / 326(4) \\
0 \cdot 8(0 \cdot 5 \text { to } 1 \cdot 4) \\
9 / 146(8) \\
1 \cdot 2(0.6 \text { to } 2 \cdot 4)\end{array}$ & $\begin{array}{l}257 / 3994(6) \\
25 / 166(15) \\
2 \cdot 6(1 \cdot 7 \text { to } 4 \cdot 0) \\
9 / 98(9) \\
1 \cdot 5(0 \cdot 7 \text { to } 2 \cdot 7) \\
16 / 73(23) \\
4 \cdot 4(2 \cdot 5 \text { to } 7 \cdot 8) \\
43 / 649(7) \\
1 \cdot 0(0 \cdot 7 \text { to } 1 \cdot 5) \\
19 / 302(6) \\
1 \cdot 0(0 \cdot 6 \text { to } 1 \cdot 6)\end{array}$ \\
\hline
\end{tabular}

Table 4 Child's allergic rhinitis in relation to one allergic disease of one of the parents and exclusion of additional allergic diseases of first degree relatives. Results are number (\%)

\begin{tabular}{|c|c|c|c|}
\hline Family history & Boys & Girls & Total \\
\hline $\begin{array}{l}\text { No allergic family history } \\
\text { One parent with allergic rhinitis } \\
\text { OR ( } 95 \% \mathrm{CI}) \\
\text { Mother with allergic rhinitis } \\
\text { OR ( } 95 \% \mathrm{CI}) \\
\text { Father with allergic rhinitis } \\
\text { OR ( } 95 \% \mathrm{CI}) \\
\text { One parent with asthma } \\
\text { OR ( } 95 \% \mathrm{CI}) \\
\text { One parent with atopic dermatitis } \\
\text { OR ( } 95 \% \mathrm{CI})\end{array}$ & $\begin{array}{l}156 / 1910(8) \\
76 / 331(23) \\
3 \cdot 4(2 \cdot 5 \text { to } 4 \cdot 5) \\
48 / 194(25) \\
3.7(2 \cdot 6 \text { to } 5 \cdot 3) \\
28 / 137(20) \\
2.9(1 \cdot 8 \text { to } 4 \cdot 5) \\
15 / 88(17) \\
2 \cdot 3(1 \cdot 3 \text { to } 4 \cdot 1) \\
18 / 159(11) \\
1.4(0.9 \text { to } 2 \cdot 4)\end{array}$ & $\begin{array}{c}84 / 2074(4) \\
49 / 327(15) \\
4 \cdot 2(2 \cdot 9 \text { to } 6 \cdot 1) \\
31 / 192(16) \\
4 \cdot 6(2 \cdot 9 \text { to } 7 \cdot 1) \\
18 / 135(13) \\
3.6(2 \cdot 1 \text { to } 6 \cdot 3) \\
9 / 82(11) \\
2.9(1 \cdot 4 \text { to } 6 \cdot 0) \\
11 / 146(8) \\
1.9(1 \cdot 0 \text { to } 3 \cdot 7)\end{array}$ & $\begin{array}{l}240 / 3984(6) \\
125 / 668(19) \\
3 \cdot 6(2 \cdot 9 \text { to } 4 \cdot 6) \\
79 / 386(21) \\
4 \cdot 1(3 \cdot 1 \text { to } 5 \cdot 4) \\
46 / 272(16) \\
3 \cdot 0(2 \cdot 1 \text { to } 4 \cdot 3) \\
24 / 170(14) \\
2 \cdot 5(1 \cdot 6 \text { to } 4 \cdot 0) \\
19 / 305(10) \\
1 \cdot 7(1 \cdot 1 \text { to } 2 \cdot 5)\end{array}$ \\
\hline
\end{tabular}

Table 5 Child's atopic dermatitis in relation to one allergic disease of one of the parents and exclusion of additional allergic diseases of first degree relatives. Results are number (\%)

\begin{tabular}{|c|c|c|c|}
\hline Family history & Boys & Girls & Total \\
\hline $\begin{array}{l}\text { No allergic family history } \\
\text { One parent with atopic dermitis } \\
\text { OR ( } 95 \% \mathrm{CI}) \\
\text { Mother with atopic dermatitis } \\
\text { OR ( } 95 \% \mathrm{CI}) \\
\text { Father with atopic dermatitis } \\
\text { OR ( } 95 \% \mathrm{CI}) \\
\text { One parent with allergic rhinitis } \\
\text { OR ( } 95 \% \mathrm{CI}) \\
\text { One parent with asthma } \\
\text { OR (95\% CI) }\end{array}$ & $\begin{array}{c}248 / 1766(14) \\
56 / 146(38) \\
3 \cdot 8(2 \cdot 7 \text { to } 5 \cdot 5) \\
44 / 102(43) \\
4 \cdot 6(3 \cdot 1 \text { to } 7 \cdot 0) \\
12 / 44(27) \\
2 \cdot 3(1 \cdot 2 \text { to } 4 \cdot 5) \\
56 / 320(18) \\
1 \cdot 3(0 \cdot 9 \text { to } 1 \cdot 8) \\
12 / 83(14) \\
1 \cdot 0(0 \cdot 5 \text { to } 1 \cdot 9)\end{array}$ & $\begin{array}{c}305 / 1924(16) \\
53 / 143(37) \\
3 \cdot 2(2 \cdot 2 \text { to } 4 \cdot 5) \\
38 / 98(39) \\
2 \cdot 4(1 \cdot 9 \text { to } 3 \cdot 2) \\
15 / 45(33) \\
2 \cdot 7(1 \cdot 4 \text { to } 5 \cdot 0) \\
70 / 310(23) \\
1 \cdot 5(1 \cdot 2 \text { to } 2 \cdot 1) \\
21 / 77(27) \\
2 \cdot 0(1 \cdot 2 \text { to } 3 \cdot 3)\end{array}$ & $\begin{array}{l}553 / 3690(15) \\
109 / 289(38) \\
3 \cdot 4(2 \cdot 6 \text { to } 4 \cdot 4) \\
82 / 200(41) \\
3 \cdot 9(2 \cdot 9 \text { to } 5 \cdot 2) \\
27 / 89(30) \\
2 \cdot 5(1 \cdot 5 \text { to } 3 \cdot 9) \\
126 / 330(20) \\
1 \cdot 4(1 \cdot 1 \text { to } 1 \cdot 8) \\
33 / 160(21) \\
1 \cdot 5(1 \cdot 0 \text { to } 2 \cdot 2)\end{array}$ \\
\hline
\end{tabular}

Table 6 Risk of asthma, allergic rhinitis, and atopic dermatitis in families with two first degree relatives with an allergic disease. Results are number (\%)

\begin{tabular}{|c|c|c|c|}
\hline Family history & Asthma & Allergic rhinitis & Atopic dermatitis \\
\hline $\begin{array}{l}\text { No allergic family history } \\
\text { Two first degree relatives } \\
\text { with allergic rhinitis/ }\end{array}$ & $257 / 3995(6)$ & $240 / 3984(6)$ & $553 / 3690(15)$ \\
\hline $\begin{array}{l}\text { atopic dermatitis } \\
\text { OR }(95 \% \mathrm{CI})\end{array}$ & $\begin{array}{c}18 / 144(13) \\
2 \cdot 1(1 \cdot 2 \text { to } 3 \cdot 5)\end{array}$ & $\begin{array}{l}27 / 144(19) \\
3 \cdot 6(2 \cdot 3 \text { to } 5 \cdot 6)\end{array}$ & $\begin{array}{c}42 / 135(31) \\
2.6(1.8 \text { to } 3 \cdot 7)\end{array}$ \\
\hline $\begin{array}{l}\text { Allergic rhinitis/asthma } \\
\text { OR }(95 \% \mathrm{CI})\end{array}$ & $\begin{array}{l}14 / 67(21) \\
3 \cdot 8(2 \cdot 1 \text { to } 7 \cdot 0)\end{array}$ & $\begin{array}{l}15 / 67(22) \\
4.5(2.5 \text { 10 } 8 \cdot 1)\end{array}$ & $\begin{array}{l}24 / 63(38) \\
3.5(2 \cdot 1 \text { (1) } 5 \cdot 9)\end{array}$ \\
\hline Atopic dermatitis/asthma & $9 / 47$ (19) & $9 / 46(20)$ & $14 / 41(34)$ \\
\hline OR $(95 \% \mathrm{CI})$ & $3.4(1.6$ to $7 \cdot 2)$ & $3.8(1.8$ to 8.0$)$ & $2.9(1.5$ to 5.6$)$ \\
\hline Asthma & $10 / 38$ & $6 / 38(16)$ & $9 / 35(26)$ \\
\hline $\mathrm{OR}(95 \% \mathrm{CI})$ & $5 \cdot 2(2 \cdot 5$ to 10.8$)$ & $2.9(1 \cdot 2$ to $7 \cdot 1)$ & $2.0(0.9 \quad 10 \quad 4.2)$ \\
\hline Allergic rhinitis & $28 / 235(12)$ & $63 / 235$ & $64 / 223$ (29) \\
\hline OR $(95 \% \mathrm{CI})$ & $2 \cdot 0(1 \cdot 3$ to $3 \cdot 0)$ & $5 \cdot 7(4 \cdot 2$ to $7 \cdot 8)$ & $2 \cdot 3(1.7$ to $3 \cdot 1)$ \\
\hline Atopic dermatitis & $22 / 174(13)$ & $21 / 174$ (12) & $71 / 168(42)$ \\
\hline OR $(95 \% \mathrm{CI})$ & $2 \cdot 1(1 \cdot 3$ to $3 \cdot 4)$ & $2 \cdot 1(1 \cdot 3$ to $3 \cdot 4)$ & $4 \cdot 1(3.0 \quad 105 \cdot 7)$ \\
\hline
\end{tabular}

diseases (table 2) we excluded allergies of other family members. In calculating the OR (tables 3-5) of the children with parents, who had different allergic diseases, only parents with a single allergy were compared with families without allergies. This correlation is shown separately for boys and girls. For each disease the highest risk for a parental allergy of the same type was analysed differentiating between the influence of the mother and the father.

Only asthma in one parent represented a risk factor for the child to develop asthma, not allergic rhinitis or atopic dermatitis (table 3). Only asthma in the father was associated with a significantly increased prevalence and OR. As expected asthma was more frequent in boys, but the risks represented by the OR were comparable with those of girls.

By excluding multiple allergies of a parent, the strongest difference was observed for the effect of atopic dermatitis in a parent. Isolated parental atopic dermatitis was associated in 6\% of cases with asthma in the child, while asthma was observed in $9 \%$ of the children (table 2) with possible additional allergies of a parent.

The highest risk for allergic rhinitis (table 4) was observed in children of parents with allergic rhinitis. The influence of the mother was a little stronger than that of the father. The risk increased slightly with parental asthma and atopic dermatitis. A higher prevalence of allergic rhinitis was observed in boys, while girls had higher OR.

Similar results were observed for atopic dermatitis in the child (table 5). Asthma and allergic rhinitis in the parents were associated with slightly higher risk, but the relationship between parental asthma and atopic dermatitis did not achieve statistical significance. Children of parents with atopic dermatitis had the most marked disposition for it, with increased OR if the mother was affected.

RISK FACTORS FOR COMBINED ALLERGIES OF TWO FAMILY MEMBERS

The risk produced by combined allergies of two family members is illustrated in table 6 . In all of these allergic diseases, the idiotypic combination resulted in the highest frequency of this allergy. The combined asthmatic disease of two first degree relatives was associated with an OR of $5 \cdot 2(95 \%$ CI $2 \cdot 5$ to $10 \cdot 8)$ for asthma. The combination of asthma and allergic rhinitis showed the highest predisposition for all three allergic diseases.

Allergic rhinitis or atopic dermatitis alone did not constitute risk factors for asthma (table 1). The combination of both was associated with an increased risk for asthma, but this was lower than in combination with an asthmatic disease of one relative.

\section{CONFOUNDERS}

The rate of reported atopic dermatitis and allergic rhinitis in the family varied greatly $(p<0.001)$ according to education, parental smoking habits, nationality, and place of residence. In families where the parents gained the 
school leaving final qualification, more family histories of atopic dermatitis or allergic rhinitis were reported $(41 \%)$ than in families where the parents had an elementary school qualification (23\%). This was also true in households without cigarette smokers (36\%) as opposed to families with smokers. $(27 \%)$ and was more so in families living in Munich (33\%) rather than in southern Bavaria (30\%). The same results were noted more often in German families (36\%) than in families of other nationalities. There was no significant difference for the rate of reported asthma cases in the family in the different groups.

To estimate the effect of the different confounding variables, the OR for allergies in the child having one family member with an allergic disease was determined in different subgroups. There was no statistically significant difference between boys or girls, whether living in Munich or southern Bavaria, with parents smoking at home or not, whether the questionnaire was filled in by the father or the mother, and between the different standard of parents' education. In nearly all of these subgroups, an OR of about 2 was observed.

\section{Discussion}

This population study showed that $40 \%$ of the children had an allergic family history and if grandparents were included this figure rose to $47 \%$. It is hence necessary to differentiate between hereditary risk factors. As $15 \%$ of the families reported combined allergies, it is important to avoid the overlapping effects by excluding additional allergies in each case. This restriction appreciably reduces the number of the children included in the different evaluations.

Data collected from questionnaires always suffer from various problems. The information given about a child or family member's atopic disease relies on memory and retrospective interpretation by the person who answered the questionnaire. However it is not possible to diagnose asthma, allergic rhinitis, or atopic dermatitis by means of a single examination of the child, because these allergic diseases occur mostly episodically. Nevertheless questionnaires offer a unique opportunity to collect information from a large and representative group in the population. As this survey comprised only chidren aged 9 to 11 years, the different groups are very comparable. It should be noted that the estimated risk for an allergic disease is valid for this age group and could vary for older children.

Earlier studies on allergic inheritance which also determined the prevalence of a family history of allergic disease in individuals with and without allergies, reported a positive family history in 40 to $80 \%$ of individuals with an allergic disease compared with $20 \%$ or fewer of individuals without an allergic disease. ${ }^{2}{ }^{15}$ Our observation that $35 \%$ of children without a reported allergic disease have a positive family history is in keeping with a surprisingly high number of children with an allergic family history.

Studies evaluating the genetic role in allergies often differentiate only between families with and without atopic diseases or take only the number of atopic family members into account. ${ }^{1617}$ Furthermore, investigations which distinguished between the genetic risk of different atopic diseases did not consider the effect of combinations of multiple allergies. $^{6} 12 \quad 1819$

In families with single allergic disease of one parent only asthma, not allergic rhinitis, is a predisposing factor for asthma in the offspring. A longitudinal study in a cohort of children aged 5-9 years observed an increase of the relative risk only for parental asthma. ${ }^{20}$ On the other hand, asthma of the mother or the father raises the risk of allergic rhinitis. This one sided relationship supports the hypothesis that allergic rhinitis could be a minor form of bronchial asthma. This is in accordance with the results of a follow up study of college students demonstrating an increased risk of developing asthma for persons with allergic rhinitis. ${ }^{21}$

The prevalence of asthma is higher in boys than in girls, but the risk factors of parental asthma are comparable for both sexes. The finding of a study of 4-6 year old children in New Zealand that parental asthma and atopic dermatitis are only associated with asthma in boys could not be confirmed by our data. ${ }^{6} 18$

The differentiation between allergies of the mother and of the father shows that for asthma in the child only paternal asthma has a strong influence, while for allergic rhinitis and atopic dermatitis the influence of the mother is more decisive. The estimated differences between the influence of the mother and of the father must be interpreted with caution, as $80 \%$ of the questionnaires were filled out by mothers. Allergies of the mother are probably overrepresented and allergies of the fathers may include more of the acute and severe type.

A cross sectional study of atopic disease in 1325 school entrants found that children whose parents have an identical type (respiratory or skin) of atopic disease more frequently develop an atopic disease $(72 \%)$ than children with nonidentical types of allergies in the parents $(21 \%) .^{16}$ We could not find a difference in the prevalence of allergies between the whole group of children with both parents allergic ( $56 \%$ ) and children of parents with an identical type of allergic manifestation (55\%). But children with two allergic family members with an identical type of allergy have the highest risk of developing that type of allergy. Combinations with different types of allergies do not show a clear relationship to one form of allergy. Additive effects also increased the risk for other types of allergic manifestations.

The proved relationship between atopy of a sibling and atopy of the examined child, which exists independently of parental disease, cannot be explained by a simple hereditary model. The increase in prevalence of allergies in children with one affected sibling and no reported parental disease and the additional increase with three or more family members compared with the group with both parents allergic could be explained by an incomplete genetic penetrance.

Various other types of studies have provided additional insight into the genetic basis of allergies. The results of case-control studies, ${ }^{11-13}$ 
which are based on clinical diagnosis, support the relationship between parental atopy and allergic disease, but due to the small numbers of cases they do not allow differentiation of family allergies.

The differences between monozygotic and dizygotic twins and a tendency for the same type of manifestations as evaluated in a large twin study provides evidence for the genetic nature of atopy. ${ }^{5}$ Concordance rates for asthma and allergic rhinitis of monozygotic twins reared apart are quite similar to those of twins reared together, suggesting a substantial genetic component for the development of asthma and allergic rhinitis. ${ }^{22}$ But twin studies are unable to identify the pattern of transmission.

Investigations of bronchial hyperreactivity using the methacholine test in healthy family members of asthmatics and in twins support the hypothesis of a separate transmission of hyperreactivity, ${ }^{23-25}$ which corresponds with the finding of a separate transmission of asthma. Family studies of serum IgE concentrations show a clear concordance, ${ }^{17}{ }^{19}$ and a genetic determination in the form of an IgE regulating gene has been suggested. ${ }^{3}$ Investigations in extended families have suggested that the propensity to produce IgE in response to common, usually inhaled, allergens is inherited as an autosomal dominant linked to chromosome $11 .^{26} 27 \mathrm{But}$ the clinical expression depends on interaction with other factors which may be, to some extent, also genetic. The concentration of IgE in an infant's cord blood has been found in many studies to predict the allergic predisposition of the child. Presumably the cord blood IgE concentration is a reflection of the genetic risk of developing atopic disease. ${ }^{15}$ Recent data about the IgG immune responsiveness to grass pollen allergen suggest that it is strongly associated with a specific HLA sequence. ${ }^{28}$

In the clinical situation it is not so important to decide whether genetic transmission is dominant, recessive, or polygenic but to estimate the increased risk in an allergic family constellation. The distinction between defined allergic family situations in this study allows a differentiated statement about the risk in certain family situations, as well as the prediction of the probable type of allergy.

Although various investigations have shown the role of genetic factors in allergies, it should be kept in mind that $23 \%$ of the children without any familial disposition also develop allergies. The study of this group of children would be of special interest in exploring the role of environmental factors.

This study was supported by the 'Bayerischen Staatsministerium für Landesentwicklung und Umweltfragen'. We would like to thank Dr E Frfr von Loeffelhol\%-Colberg, Professor Dr
W Lehmacher, and Dr T Nicolai for planning and supervising this study; all 182 participating schools for their support of the this study; all 182 participating schools for their support of the
study, as well as the children and their parents, whose commitstudy, as well as the children and
ment was essential for the survey.

1 Coca AF, Cooke RA. On the classification of the phenomen of hypersensitiveness. F Immunol 1923;8:163-71.

2 Bray GW. The hereditary factor of asthma and other allergies. BMF 1930;i:384-7.

3 Marsh DG, Meyers DA, Bias WB. The epidemiology and genetics of atopic allergy. $N$ Engl $\mathcal{F}$ Med 1981;305:1551-9.

$4 \mathrm{Kjellman} M$. Prediction and prevention of atopic allergy. Allergy 1982;37:463-73.

5 Edfors-Lubs ML. Allergy in 7000 twin pairs. Acta Allergol $1971 ; 26: 249-85$.

6 Fergusson DM, Horwood LJ, Shannon FT. Parental asthma, parental eczema and asthma and eczema in early childhood. fournal of Chromic Diseases 1983;36:517-24.

7 Blumenthal MN, Amos DB. Genetic and immunologic basis of atopic responses. Chest 1987;91:176-84.

8 Levitt RC, Mitzner W, Kleeberger SR. A genetic approach to the study of lung physiology: understanding biologica variability in airway responsiveness. Am f Physiol 1990 258:157-64.

9 McConnochie KM, Roghmann KJ. Parental smoking, presence of older siblings, and family history of asthma increase risk of bronchiolitis. Am $\mathcal{J}$ Dis Child 1986;140 806-12.

10 Pöysä L. Atopy in children with and without a family history of atopy. II. Skin reactivity. Acta Paediatr Scand 1989;78 902-6.

11 Sibbald B, Horn MEC, Gregg IA. Family study of the genetic basis of asthma and wheezy bronchitis. Arch Dis Child 1980;55:354-7.

12 Luoma R, Koivikko A, Viander M. Development of asthma, allergic rhinitis and atopic dermatitis by the age of five years. Allergy 1983;38:339-46.

13 Kuester W, Petersen M, Christophers E, Goos M, Sterry W. A family study of atopic dermatitis. Clinical and genetic A family study of atopic dermatitis. Clinical and genetic characteristis of 188 patients and
Arch Dermatol Res 1990;282:98-102.

14 von Mutius E, Dold S, Wist M, et al. Münchener Asthma und Allergiestudie. Prävalenzen atopischer und asthmatischer Erkrankungen im Kindesalter in Bayern. Müncher Medizinische Wochenschrift 1991;133:675-9.

15 Ownby DR. Environmental factors versus genetic determinants of childhood inhalant allergies. $\mathcal{f}$ Allergy Clin Immunol 1990;86:279-89.

16 Kiellman M. Atopic disease in seven-year-old children. Acto Paediatr Scand 1977;66:465-71.

17 Turner KJ, Rosman DL, O'Mahony J. Prevalence and familial association of atopic disease and its relationship to serum IgE levels in 1061 school children and their families.
s. International Archives of Allergy 1974;47:650-64.

18 Horwood LJ, Fergusson DM, Shannon FT. Social and familial factors in the development of early childhood familial factors in the development

19 Lebowitz MD, Barbee R, Burrows B. Family concordance of IgE, atopy, and disease. $\mathcal{F}$ Allergy Clin Immunol 1984;73 259-64.

20 Sherman CB, Tosteson TD, Tager IB, Speizer FE, Weiss ST. Early childhood predictors of asthma. Am $\mathcal{F}$ Epidemio 1990;132:83-95.

21 Hagy GW, Settipane GA. Risk factors for developing asthma and allergic rhinitis. $\mathcal{F}$ Allergy Clin Immunol 1976;58:330-6

22 Hansson B, McGue M, Roitman-Johnson B, Segal NL, Bouchard TJ, Blumenthal MN. Atopic disease and immunoglobulin $\mathrm{E}$ in twins reared apart and together. $A m$
F Hum Genet 1991;48:873-9.

23 Konig P, Godfrey S. Exercise-duffed bronchial ability in monozygotic (identical) and dizygotic (non-identical) twins. monozygotic (identical) and dizygotic

24 Hopp RJ, Bewtra AK, Watt GD, Nair NM, Townley RG Genetic analysis of allergic disease in twins. $\mathcal{f}$ Allergy Clin Immunol 1984;73:265-70

25 Longo G, Strinati R, Poli F, Fumi F. Genetic factors in nonspecific bronchial hyperactivity. Am $\mathcal{F}$ Dis Child 1987 141:331-4.

26 Cookson WOCM, Hopkin JM. Dominant inheritance of atopic immunoglobulin-E responsiveness. Lancet 1988; 86-8.

27 Cookson WOCM, Sharp PA, Faux JA, Hopkin JM. Linkage between immunoglobulin $E$ responses underlying asthm and rhinitis and chromosome 11 q. Lancet 1989;i:1292-5.

28 Ansari AA, Shinomiya N, Zwollo P, Marsh DG. HLA-D gene studies in relation to immune responsiveness to a grass
allergen Lol p III. Immunogenetics 1991;33:24-32. 